\title{
Community-based health insurance and
}

\section{communities' scheme requirement compliance in Thehuldere district, northeast Ethiopia: cross-sectional community-based study}

\author{
This article was published in the following Dove Press journal: \\ ClinicoEconomics and Outcomes Research \\ 14 June 2017 \\ Number of times this article has been viewed
}

\section{Samuel Getachew \\ Workneh' \\ Gashaw Andargie Biks ${ }^{2}$ \\ Solomon Assefa Woreta ${ }^{3}$ \\ 'Clinton Health Access Initiative Child Survival Program, Bahir Dar, Ethiopia; ${ }^{2}$ Department of Health Management and Health Economics, College of Medicine and Health Sciences, University of Gondar, Gondar, Ethiopia; ${ }^{3}$ Department of Health Informatics, College of Medicine and Health Sciences, University of Gondar, Gondar, Ethiopia}

Correspondence: Solomon Assefa Woreta

University of Gondar, Institute of Public Health, PO Box 1480, Gondar, Ethiopia $\mathrm{Tel}+251$ 9I 8775250

Email solomonazezo@gmail.com
Background: Community-based health insurance (CBHI) is becoming a prominent and promising concept in tackling financial health care issues confronting the poor rural communities in developing countries. Ethiopia endorsed and constituted CBHI schemes in 13 pilot "woredas" in 2010/11. This study aimed to assess the compliance of the community to CBHI scheme requirements in Thehuledere district, northeast Ethiopia.

Methods: A community-based cross-sectional study was conducted among 530 respondents between April and June 2015 in Thehuledere District, South Wollo Zone, northeast Ethiopia. A systematic random sampling technique was deployed to select the study participants. A selfadministered, structured, pre-tested questionnaire was used to collect the data. Bivariate and multivariate logistic regression analyses were used to identify factors associated with $\mathrm{CBHI}$ compliance.

Results: A total of 511 study participants were included in the study. Approximately $77.9 \%$ of the study population complied with $\mathrm{CBHI}$ requirements: members' age ( $\mathrm{AOR}=0.74,95 \% \mathrm{CI}$ : 0.62-0.8), premium fee affordability (AOR: $2.66,95 \%$ CI: [1.13-4.42]), members' occupation $(\mathrm{AOR}=0.14,95 \% \mathrm{CI}: 0.04-0.45)$, members' attitude toward $\mathrm{CBHI}$ management $(\mathrm{AOR}=2.11$ [1.14-3.90]), and CBHI members' knowledge ( $\mathrm{AOR}=0.24,95 \% \mathrm{CI}$ : [0.13-0.42]) were found to be major predictors of community compliance to $\mathrm{CBHI}$ requirements.

Conclusion: $\mathrm{CBHI}$ requirement compliance at the early stage was relatively high. We observed that members' age, premium fee affordability, occupation, attitude, and knowledge were significant predictors. CBHI management's involvement in awareness creation and training on requirements of the CBHI scheme would contribute to better outcomes and success.

Keywords: compliance, community-based health insurance, Ethiopia

\section{Introduction}

Community-based health insurance (CBHI) is a pledge agreement requiring the health insurer to cover basic health service costs in exchange for premium payments into a collective fund which is designed, owned, and administered by members. ${ }^{1}$

No country in the world is able to fully provide health cover to citizens effectively due to a lack of spending money for health care services. The World Health Organization (WHO) stated the pressing situation as 150 million people worldwide suffer a financial calamitous shock each year, and more than 100 million are nudged into poverty due to direct payments for health care-related services. ${ }^{1}$ Among the advanced countries, reports showed that even the USA cannot offer health service cover to all citizens, and 46 million Americans have insufficient health services coverage. ${ }^{2}$ 
Health insurance implemented in developed countries benefits people through available prompt medical care, improving their health status, providing better health outcomes, reducing the physical burden for the insured and the demand for free-cost care from the provider. ${ }^{3} \mathrm{CBHI}$ as a system of health insurance is designed to ameliorate health care service encounters of destitute and informal sector employees. Implementation of CBHI in Asia and central Africa is accredited with providing benefits such as protecting the destitute against extraordinary health care services costs, providing financial safety for the poor, minimizing the equity gap, reducing out-of-pocket spending, building members' self-belief through community control procedures with its design and implementation challenges. ${ }^{4}$

Enormous initiatives were used to expand the $\mathrm{CBHI}$ in developing countries, and initiatives employed to help people went on further than the experimental stage because of many impediments, mainly a challenge of enrollment and poor adherence to scheme requirements as a consequence of the variable training and attitudes of the volunteers..$^{5-8}$

Implementation studies carried out in Asia and Africa on CBHI schemes indicated that the performance, as planned in the design phase, was not adequate, wasted resources resulted in the loss of trust among the members. The method being implemented in Nepal is not promising as the scope and impact are very limited. ${ }^{9}$ In Cameroon there are difficulties such as a sustainable existence ${ }^{10}$ and in Burkina Faso the high drop-out rate of the members has been documented. ${ }^{11}$ SubSaharan Africa is well-known to have a high burden of disease and low government expenditure on health. The accessibility of CBHI schemes largely exhibited weak presentation. ${ }^{12}$

Health in Ethiopia has improved noticeably in the last few decades, with government leadership playing a significant role in mobilizing resources and ensuring they are used efficiently. The government has recognized CBHI for financing health care services and cutting out-of-pocket spending for medical care. CBHI was piloted 4 years ago in four regions in Ethiopia, accounting for $85 \%$ of the total population. ${ }^{13}$ Under the CBHI system, each district or "woreda" will have a collective health fund to which participants will contribute. The poor are eligible for membership in community health funds sponsored by the "woredas" and regions. ${ }^{14,15}$

The infancy stage of CBHI studies in piloted areas revealed that the scheme benefited members by reducing the need to borrow money for medical care, improving outpatient care, seeking ever increasing enrollment, and a better willingness to pay than other East African countries. In effect, expansion to another district is commencing. However, the adherence of the members' to the article of the association of the scheme, which severely affects the sustainable implementation, has still not been studied thoroughly. ${ }^{14,15}$ This study therefore aimed to investigate the compliance of CBHI members' to scheme requirements and possible associated factors in the Thehuledere district, South Wollo Zone, northeast Ethiopia.

\section{Materials and methods Study design and setting}

A community-based cross-sectional study was carried out between April 20 and June 10, 2015, in Thehuledere district of South Wollo Zone. Thehuledere district is one of the 23 districts of South Wollo Zone, Amhara National Regional State, in northeast Ethiopia. It is among the three districts of Amhara region where the CBHI scheme was first introduced in June 2011. It has a total of 21 rural "kebeles" with 19,455 households of which 18,219 are members of the CBHI (94\% enrollment rate). This district currently has 21 health posts, six small private clinics, three medium private clinics, five public health centers, seven drug stores, and one diagnostic laboratory facility, as reported by the District Health Office in the 2014 fourth quarter report. CBHI member households have all lived in the rural area of the selected "kebeles" for more than 6 months and willingly gave consent to be included in this study. Respondents who were working in a formal community organization in the rural community were excluded from the study.

\section{Sample size and sampling procedure}

The sample size was computed using Epi Info version 3.5.3 by considering the proportion (p) $94 \%$ of CBHI, obtained from Ethiopian National Health Insurance Survey (2005), ${ }^{16}$ a design effect of 2 for multistage sampling, a 10\% non-response rate, and a margin of error of $3 \%$. The final sample size was 530 .

A multistage sampling technique was used. In the first stage six "kebeles", according to the number of "kebeles" in each of the pilot categories, were selected using simple random sampling technique from 21 rural "kebeles", and the sample sizes were distributed in proportion to the number of households each "kebele" has. The number of "kebeles" included in the sample was dependent on the inclusion of an adequate number of households - at least $20 \%$ of "kebeles". In the second stage, study participants were selected using systematic random sampling technique. The registration number from the list of CBHI membership issued to each 
house in the "kebeles" by the district's CBHI office was utilized as a sampling frame.

\section{Data collection procedures}

Data were collected using a structured, self-administered questionnaire, which was initially prepared in English and translated into the local language, Amharic, by those proficient in the language, and checked for consistency. Five percent of the questionnaires were pre-tested prior to the actual data collection period in a comparable setting. Training and appropriate supervision of data collectors were employed to control data quality. Supervisors and principal investigators oversaw the data collection daily.

\section{Data processing and analysis}

The questionnaires completed by respondents were checked for completeness and consistency, then coded, and entered into Epi Info 3.5.3 and exported to SPSS version 20 statistical software for final analysis. Descriptive statistics were used to describe the study population correlated to relevant variables and presented using text, table, frequency, and percentage. Both bivariate and multivariate logistic regression models were used to find associated factors with the outcome variable at $p$-value $\leq 0.2$. Variables significant at $p$-value 0.05 level and AOR with $95 \% \mathrm{CI}$ were considered as factors associated with community compliance to $\mathrm{CBHI}$ requirements.

\section{Ethical considerations}

Ethical clearance was obtained from the Institutional Review Board of the University of Gondar, College of Medicine and Health Sciences together with a permission letter approved by Thehuledere district health office, South Wollo Zone, and all selected study "kebeles". Each study participant was briefed on the study objective and verbal consent was granted.

\section{Results}

\section{Socio-demographic characteristics of participants}

A total of $511 \mathrm{CBHI}$ household members were included in the study with a response rate of $96.4 \%$. The other $3.4 \%$ of participants were either non-responsive or excluded due to incomplete data. The majority, 351 (68.7\%), were within the age range from 40 to 60 years, $420(82.2 \%)$ were male, 448 $(87.7 \%)$ were married, and about half of the participants, 229 (44.8\%), were illiterate, the Muslim religion was practiced by $445(87.1 \%)$, and $338(66 \%)$ of the study participants' monthly income was less than 500 ETB. More than half
$(349,68.3 \%)$ of household members had a family size of 3-5 people, Table 1 .

Table I Socio-demographic characteristics of community-based health insurance members (April 2015-June 2015)

\begin{tabular}{|c|c|c|c|}
\hline Characteristics & Variables & Frequency (n) & Percent \\
\hline \multirow[t]{2}{*}{ Sex } & Female & 91 & 17.8 \\
\hline & Male & 420 & 82.2 \\
\hline \multirow[t]{5}{*}{ Age } & $18-30$ & 36 & 7.0 \\
\hline & $30.1-40$ & 96 & 18.8 \\
\hline & $40.1-50$ & 197 & 38.6 \\
\hline & $50.1-60$ & 154 & 30.1 \\
\hline & $>60$ & 28 & 5.5 \\
\hline \multirow[t]{2}{*}{ Religion } & Muslim & 445 & 87.1 \\
\hline & Orthodox & 66 & 12.9 \\
\hline \multirow[t]{4}{*}{ Marital status } & Single & 16 & 3.1 \\
\hline & Married & 448 & 87.7 \\
\hline & Widowed & 2 & 0.4 \\
\hline & Separated & 45 & 8.8 \\
\hline Ethnicity & Amhara & 511 & 100.0 \\
\hline \multirow[t]{4}{*}{ Educational status } & Illiterate & 229 & 44.8 \\
\hline & $\begin{array}{l}\text { Able to read } \\
\text { and write }\end{array}$ & 207 & 40.5 \\
\hline & Elementary & 65 & 12.7 \\
\hline & High school & 10 & 2.0 \\
\hline Monthly average & $<500$ & 338 & 66.1 \\
\hline \multirow[t]{5}{*}{ income } & $50 I-750$ & 113 & 22.1 \\
\hline & $751-1,000$ & 33 & 6.5 \\
\hline & $I, 001-1,250$ & 14 & 2.7 \\
\hline & $|, 25|-\mid, 500$ & 4 & 0.8 \\
\hline & $>1,500$ & 9 & 1.8 \\
\hline \multirow[t]{3}{*}{ Family size } & $<3$ & 67 & 13.1 \\
\hline & $3-5$ & 349 & 68.3 \\
\hline & $6-8$ & 95 & 18.6 \\
\hline
\end{tabular}

\section{$\mathrm{CBHI}$ health institutions service}

The majority of the household members recognized that health centers $(479,93.8 \%)$ and hospitals $(444,86.9 \%)$ entered into a contract to treat members within the acceptable distance range. A total of 181 (35.4\%) household members visited the health institutions with one sick person within a month, and 185 (36.2\%) were sick for 1-5 days. Approximately three quarters $(391,76.5 \%)$ of the household members agreed that the health care providers favored CBHI members in the course of treatments and about half $(251,49.1 \%)$ of the household members agreed the total CBHI members' cost of care was tolerable, with the large majority of the households $(480,93.9 \%)$ being self-sponsored. Prior to a fully-fledged CBHI enrollment, 429 (84\%) of the study participants attended CBHI meetings, 244 (47.7\%) respondents participated in CBHI-related training, and 234 (45.8\%) had knowledge about CBHI. From the overall respondents, 461 $(90.2 \%)$ accepted the registration fee, $442(86.5 \%)$ of the respondents stated the premium fees were affordable, 479 
Table 2 Community-based health insurance health institution service (April 20I5-June 20I5)

\begin{tabular}{|c|c|c|c|}
\hline Variables & Response & Frequency (n) & Percent \\
\hline \multirow[t]{2}{*}{ Knowledge about $\mathrm{CBHI}$} & Poor & 277 & 54.2 \\
\hline & Good & 234 & 45.8 \\
\hline \multirow[t]{4}{*}{ Health institutions visits for the last month } & once & 181 & 34.4 \\
\hline & Twice & 47 & 9.2 \\
\hline & Thrice & 2 & 0.4 \\
\hline & None & 281 & 55 \\
\hline \multirow[t]{4}{*}{ Total number of members' sick days } & $\mathrm{I}-5$ & 185 & 36.2 \\
\hline & $2-10$ & 24 & 4.7 \\
\hline & $>10$ & 21 & 4.1 \\
\hline & None & 281 & 55 \\
\hline \multirow[t]{2}{*}{ Do health care workers favor members? } & No & 99 & 19.4 \\
\hline & Yes & 412 & 80.6 \\
\hline \multirow[t]{2}{*}{ Is the cost of care high even if household is enrolled in CBHI scheme? } & No & 260 & 50.9 \\
\hline & Yes & 251 & 49.1 \\
\hline \multirow[t]{2}{*}{ Who paid for registration and renewal? } & Self-sponsor & 480 & 93.9 \\
\hline & Government & 31 & 6.1 \\
\hline \multirow[t]{2}{*}{ Received CBHI-related training before enrollment } & No & 266 & 52.1 \\
\hline & Yes & 244 & 47.7 \\
\hline \multirow[t]{2}{*}{ Did you attend meetings before enrollment? } & No & 82 & 16 \\
\hline & Yes & 429 & 84 \\
\hline \multirow[t]{2}{*}{ Planned to renew $\mathrm{CBHI}$} & No & 28 & 5.5 \\
\hline & Yes & 483 & 94.5 \\
\hline \multirow[t]{2}{*}{$\mathrm{CBHI}$ registration fee affordable } & No & 50 & 9.8 \\
\hline & Yes & 461 & 90.2 \\
\hline \multirow[t]{2}{*}{$\mathrm{CBHI}$ premium fee affordable } & No & 69 & 13.5 \\
\hline & Yes & 442 & 86.5 \\
\hline \multirow[t]{2}{*}{$\mathrm{CBHI}$ registration service satisfaction level } & Poor & 32 & 6.3 \\
\hline & Good & 479 & 93.7 \\
\hline \multirow[t]{2}{*}{$\mathrm{CBHI}$ health facilities provided a good service } & No & 137 & 26.8 \\
\hline & yes & 374 & 73.2 \\
\hline \multirow[t]{2}{*}{ Attitude toward $\mathrm{CBHI}$ management } & Negative & 95 & 18.6 \\
\hline & Positive & 416 & 81.4 \\
\hline \multirow[t]{2}{*}{ Overall CBHI service level } & Poor & 48 & 9.4 \\
\hline & Good & 463 & 90.3 \\
\hline
\end{tabular}

Abbreviation: $\mathrm{CBHI}$, community-based health insurance.

(93.7\%) were satisfied by the registration service, and 439 (85.9\%) believed the premium collection place was comfortable. Similarly, $416(81.4 \%)$ believed the management to be trustworthy and the majority $(463,90.6 \%)$ were satisfied by the overall CBHI service, Table 2.

\section{Compliance of $\mathrm{CBHI}$ members}

Among the 94 (18\%) CBHI members who lost their CBHI cards, $81(86.2 \%)$ of the respondents replaced their CBHI cards during the allotted time frame. A large proportion of CBHI-enrolled members $(471,92.2 \%)$ renewed their membership during the scheduled time frame with a $7.8 \%$ dropout rate, $453(88.6 \%)$ member household representatives attended $75 \%$ of the annual meetings, 386 (85.1\%) members acknowledged the $\mathrm{CBHI}$ regulations do not conflict with their religion, and 480 (96.1\%) of the CBHI members believed the whole community benefited from the CBHI program. Generally, the majority of the respondents $(398,77.9 \%)$ were complying with the $\mathrm{CBHI}$ requirements, Figure 1.

\section{Factors associated with compliance to $\mathrm{CBHI}$ requirements}

The result of the multivariate logistic regression model revealed that occupation, age, CBHI membership fee affordability, $\mathrm{CBHI}$ renewal period, knowledge regarding $\mathrm{CBHI}$, and the attitude toward the $\mathrm{CBHI}$ management were significantly associated with compliance to $\mathrm{CBHI}$ requirements.

The study showed that those CBHI members aged 50-59 years old were less likely to comply with $\mathrm{CBHI}$ requirements when compared with those $\mathrm{CBHI}$ members who were less than 20 years old $(\mathrm{AOR}=0.14,95 \% \mathrm{CI}$ : $[0.05-0.45])$. Similarly, $\mathrm{CBHI}$ members who planned to renew their membership 
were 26 times more likely to comply with $\mathrm{CBHI}$ requirements when compared with their counterparts $(\mathrm{AOR}=25.5,95 \% \mathrm{CI}$ : [7.8-83.6]). In addition, the study participants who agreed on $\mathrm{CBHI}$ premium fee affordability were three times more likely to comply with $\mathrm{CBHI}$ requirements when compared with those respondents who disagreed (AOR: 2.66, 95\% CI: [1.13-4.42]). Being a merchant, you were less likely

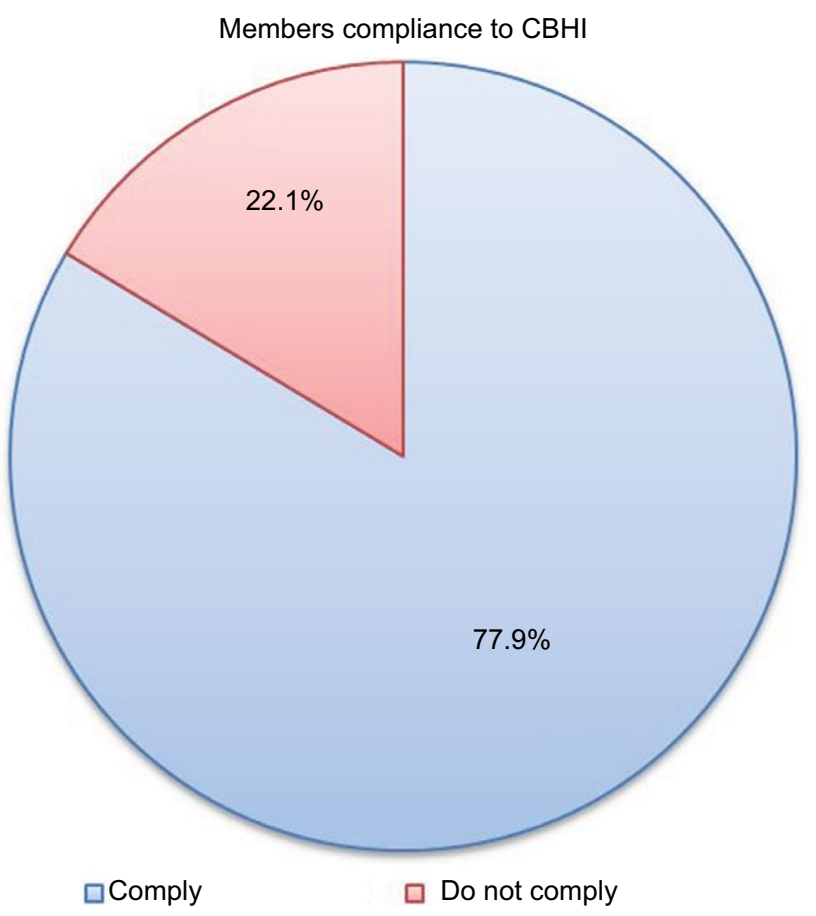

Figure I Pie chart of members' compliance with community-based health insurance scheme requirements (April 2015-June 2015).

Abbreviation: $\mathrm{CBHI}$, community-based health insurance. to comply with $\mathrm{CBHI}$ requirements when compared with farmers $(\mathrm{AOR}=0.18,95 \% \mathrm{CI}$ : [0.09-0.64]). However, $\mathrm{CBHI}$ members who had a positive attitude toward CBHI management were twice as likely to comply with $\mathrm{CBHI}$ requirements than those members who had a negative attitude $(\mathrm{AOR}=2.11$ [1.14-3.90]). Moreover, study participants who were not knowledgeable about CBHI were $76 \%$ less likely to comply with $\mathrm{CBHI}$ requirements when compared with knowledgeable members $(\mathrm{AOR}=0.24,95 \% \mathrm{CI}$ : [0.13-0.42]), Table 3 .

\section{Discussion}

Enormous momentum has been gained after the WHO endorsed a resolution encouraging countries to advance toward universal health coverage. ${ }^{17,18}$ This changeover refers to a shift from financing health care through out-of-pocket payments toward health insurance and risk pooling schemes, to make sure the entire population has affordable access to basic health interventions with no risk of destitution. ${ }^{19}$ The Ethiopian government endorsed and launched CBHI schemes in 13 pilot "woredas" in Amhara, Oromia, Southern Nations, Nationalities and Peoples, and Tigray regions in 2010/11, Thehuledere district, northeast Ethiopia is one of the 13 pilot "woredas" in the Amhara region.

The overall CBHI enrollment rate of Thehuledere district was found to be $94 \%$, which is less than that of Yirgalem $(100 \%)$, but better than the other piloted districts in Ethiopia - 67\% in Dimbitchu and Damboya, 62\% in south Achefere, and $38 \%$ in Fogera. ${ }^{13}$ The CBHI renewal rate in this study was found to be $92.2 \%$, which has progressed from $82 \%$ in the study conducted in the Ethiopian piloted $\mathrm{CBHI}$ areas in

Table 3 Factors associated with members' compliance with community-based health insurance requirements (April 20I5-June 20I5)

\begin{tabular}{|c|c|c|c|c|c|c|}
\hline \multirow[t]{2}{*}{ Characteristics } & \multicolumn{3}{|c|}{ Compliance to CBHI } & \multirow[t]{2}{*}{$p$-Value } & \multirow[t]{2}{*}{ COR (95\% CI) } & \multirow[t]{2}{*}{ AOR (95\% Cl) } \\
\hline & & No & Yes & & & \\
\hline \multirow[t]{6}{*}{ Age } & $<20$ & 8 & 45 & I & & \\
\hline & $20-29$ & 9 & 27 & 0.029 & $0.53(0.18-1.50)$ & $0.24(0.06-0.87)^{*}$ \\
\hline & $30-39$ & 12 & 74 & 389 & $1.09(0.42-2.89)$ & $0.59(0.18-1.96)$ \\
\hline & $40-49$ & 40 & 136 & 0.003 & $0.6 \mathrm{I}(0.26-\mathrm{I} .39)$ & $0.19(0.07-0.58)^{*}$ \\
\hline & $50-59$ & 32 & 97 & 0.001 & $0.54(0.23-1.26)$ & $0.14(0.05-0.45)^{*}$ \\
\hline & $>60$ & 12 & 19 & 0.017 & $0.28(0.10-0.80)$ & $0.20(0.05-0.76)^{*}$ \\
\hline Willingness to renew CBHI & No & 24 & 4 & I & & \\
\hline membership & Yes & 89 & 394 & 0.000 & $26.6(9.00-78.5)$ & $25.54(7.80-83.63)^{*}$ \\
\hline \multirow[t]{2}{*}{$\mathrm{CBHI}$ premium affordable } & No & 27 & 86 & I & & \\
\hline & Yes & 42 & 356 & 0.000 & $1.68(0.70-4.0)$ & $2.66(1.5-4.6)^{*}$ \\
\hline \multirow[t]{2}{*}{ Occupation } & Farmer & 106 & 390 & I & & \\
\hline & Merchant & 7 & 8 & 0.008 & $0.3 I(0.1 I-0.88)$ & $0.18(0.09-0.64)^{*}$ \\
\hline Attitude toward & Negative & 33 & 62 & I & & \\
\hline management & Positive & 80 & 336 & 0.018 & $2.24(1.37-3.64)$ & $2.11(1.14-3.91)^{*}$ \\
\hline \multirow[t]{2}{*}{ Knowledge } & Good & 34 & 200 & I & & \\
\hline & Poor & 79 & 198 & 0.000 & $0.34(0.18-0.66)$ & $0.24(0.13-0.42)^{*}$ \\
\hline
\end{tabular}

Note: *indicates variables which show significant association in multivariate analysis. 
April 2013, and is similar to the study conducted in Rwanda $(90 \%){ }^{16,19}$

Generally, household members' compliance to the CBHI requirements in this study was $77.9 \%$, with $94 \%$ enrollment rate, $92.2 \%$ renewal rate $(7.8 \%$ drop-out rate), and $88.6 \%$ participation rate in CBHI-involved meetings.

This study also showed the occupational status of CBHI members had a significant association with their compliance to CBHI requirements. Merchants $(439,86 \%)$ were less likely to comply with $\mathrm{CBHI}$ requirements when compared with farmers, which is supported by the study conducted in the Edo state of Nigeria where $83 \%$ were less likely to take part in CBHI schemes. ${ }^{20}$ This is probably due to the fact that households headed by merchants were more likely to have fewer anxieties or worries about their ability to pay for health expenses, with no enrollment and active participation in a CBHI scheme, they presumed that they have the financial ability to cover their health care costs. However, a similar study conducted in a rural part of Bahir and Uttar Pradesh in India showed, contrarily, that the household head's occupation did not appear to impact the participation in CBHI schemes, and this might be due to the difference in socio-cultural and economic characteristics. ${ }^{21}$

In our study, household members' age was a significant factor for members' compliance with the CBHI scheme, older members were less likely to comply with CBHI scheme requirements when compared with those members aged less than 20 years, this finding is similar to the studies conducted in rural areas in Senegal, Edo state of Nigeria and Bahir and Uttar Pradesh in India. ${ }^{20-22}$

However, different studies indicated that age does not seem to have any impact, previously there have been no age categories. ${ }^{23}$ This could be due to older people being excluded from the community economically and socially more often, and as a result, they find it more challenging to take part in CBHI schemes. ${ }^{24}$ Similarly, older people would be alacritous to pay less than younger people for shared health insurance. ${ }^{25}$

Similarly, the study participants who had poor knowledge about the CBHI schemes were less likely to comply with the $\mathrm{CBHI}$ requirements, this finding is in line with the study conducted in south Ethiopia on CBHI pilot schemes and could be explained by poor knowledge, this would contribute to the strengthening of members' incredulity toward CBHI schemes, and would negatively influence participation. On the contrary, an efficient information campaign and provision of training would contribute to build members' trust in CBHI scheme management and promote the retention of members. ${ }^{16}$
This study also illustrates that household members' willingness to renew (94.5\%) CBHI membership was one of the predictors for members' compliance, with a strong positive statistical association. This is similar to the study conducted in Nigeria $(83.9 \%) .{ }^{26}$ This might be due to the affordable premium registration fee and the satisfaction with the health care service offered.

Moreover, CBHI members who had positive attitudes toward CBHI management, were more likely to comply with $\mathrm{CBHI}$ requirements, which is similar to the study conducted in the Edo state of Nigeria, and the possible reason for this could be members' trust in the scheme benefits, the management, and health facilities which are providing health services to the members. ${ }^{20}$

The validity of the study may be inadequate due to its cross-sectional instead of longitudinal study design. Though this is the first study of its kind in the study area, we believe it creates cognizance in Ethiopia and provides useful information for the existing health care service.

\section{Conclusion}

These study findings revealed that the level of members' compliance with $\mathrm{CBHI}$ requirements is encouraging when considering the performance and implementation stage of the program. Members' compliance to $\mathrm{CBHI}$ scheme requirements was influenced by age, premium fee affordability, occupation, willingness to renew membership, attitude toward CBHI management, and knowledge of the scheme. These findings will be informative for government and policymakers to improve CBHI operations, and increase usage rates by providing technical support to $\mathrm{CBHI}$ managers, helping legitimize existing schemes, and improving public awareness regarding the concept of insurance.

\section{Acknowledgments}

We thank our study participants who volunteered and used their time to give us all the relevant information for the study, and the data collectors whose invaluable effort was crucial to obtain relevant data.

\section{Author contributions}

All authors contributed towards data analysis, drafting, and revising the paper and agree to be accountable for all aspect of work.

\section{Disclosure}

The authors report no conflicts of interest in this work. 


\section{References}

1. Uzochukwu BS, Ughasoro MD, Etiaba E, Okwuosa C, Envuladu E, Onwujekwe OE. Health care financing in Nigeria: implications for achieving universal health coverage. Niger J Clin Pract. 2015;18(4): 437-444.

2. Sura A, Shah NR. Pay-for-performance initiatives: modest benefits for improving healthcare quality. Am Health Drug Benefits. 2010;3(2): $135-142$.

3. Institute of Medicine (US) and National Academy of Engineering (US) Roundtable on Value \& Science-Driven Health Care. Engineering $a$ Learning Healthcare System: A Look at the Future: Workshop Summary. Washington (DC): National Academies Press (US); 2011.

4. Jacobs B, Bigdeli M, van Pelt M, Ir P, Salze C, Criel B. Bridging community-based health insurance and social protection for health care--a step in the direction of universal coverage? Trop Med Int Health. 2008;13(2): 140-143.

5. Kirigia JM, Sambo LG, Nganda B, Mwabu GM, Chatora R, Mwase T. Determinants of health insurance ownership among South African women. BMC Health Serv Res. 2005;5(1):17.

6. Alkenbrack S, Jacobs B, Lindelow M. Achieving universal health coverage through voluntary insurance: what can we learn from the experience of Lao PDR? BMC Health Serv Res. 2013;13:521.

7. Adebayo EF, Ataguba JE, Uthman OA, Okwundu CI, Lamont KT, Wiysonge CS. Factors that affect the uptake of community-based health insurance in low-income and middle-income countries: a systematic protocol. BMJ Open. 2014;4(2):e004167.

8. Dror DM, Hossain SA, Majumdar A, Perez Koehlmoos TL, John D, Panda PK. What factors affect voluntary uptake of community-based health insurance schemes in low- and middle-income countries? A systematic review and meta-analysis. PLoS One. 2016;11(8):e0160479.

9. Ghimire R. Community based health insurance practices in Nepal. International Research and Reviews. 2013;2(4).

10. Adebayo EF, Uthman OA, Wiysonge CS, Stern EA, Lamont KT, Ataguba JE. A systematic review of factors that affect uptake of community-based health insurance in low-income and middle-income countries. BMC Health Serv Res. 2015;15:543.

11. Hounton S, Byass P, Kouyate B. Assessing effectiveness of a community based health insurance in rural Burkina Faso. BMC Health Serv Res. 2012;12:363.

12. Odeyemi IA. Community-based health insurance programmes and the national health insurance scheme of Nigeria: challenges to uptake and integration. Int J Equity Health. 2014;13:20.

13. Ethiopian Health Insurance Agency. Evaluation of Community-Based Health Insurance Pilot Schemes in Ethiopia. 2015 May. Available from https://www.hfgproject.org/wp-content/uploads/2015/05/CBHIEvaluation-5-2015.pdf. Accessed September 6, 2015.
14. Mebratie AD, Sparrow R, Yilma Z, Abebaw D, Alemu G, Bedi A. Impact of Ethiopian pilot community-based health insurance scheme on health-care utilisation: a household panel data analysis. The Lancet. 2013;381:S92.

15. Haile M, Ololo S, Megersa B. Willingness to join community-based health insurance among rural households of Debub Bench District, Bench Maji Zone, Southwest Ethiopia. BMC Public Health. 2014;14:591.

16. Mebratie AD, Sparrow R, Yilma Z, Alemu G, Bedi AS. Dropping out of Ethiopia's community-based health insurance scheme. Health Policy Plan. 2015;30(10):1296-1306.

17. WHO. Resolution of the World Health Assembly. Sustainable Health Financing, Universal Coverage and Social Health Insurance. Geneva, Switzerland; Report No. Resolution WHA58.33. Available from http:// apps.who.int/iris/bitstream/10665/20383/1/WHA58_33-en.pdf?ua=1. Accessed March 15, 2015.

18. Rodin J, de Ferranti D. Universal health coverage: the third global health transition? Lancet. 2012;380(9845):861-862.

19. Shimeles A. Community based health insurance schemes in Africa: The case of Rwanda. Available from: https://gupea.ub.gu.se/handle/2077/23064. Working Papers in Economics 463; 2010. Accessed May 22, 2017.

20. Oriakhi HO, Onemolease EA. Determinants of rural household's willingness to participate in community based health insurance scheme in Edo State, Nigeria. Ethno-Medicine. 2012;6(2):95-102.

21. Panda P, Chakraborty A, Dror DM, Bedi AS. Enrolment in communitybased health insurance schemes in rural Bihar and Uttar Pradesh, India. Health Policy Plan. 2014;29(8):960-974.

22. Jutting J. Health Insurance for the Poor? Determinants of Participation in Community-Based Health Insurance Schemes in Rural Senegal. OECD Development Centre Working Paper No 204; 2003. Available from: http://www.gsdrc.org/document-library/health-insurance-forthe-poor-determinants-of-participation-in-community-based-healthinsurance-schemes-in-rural-senegal/. Accessed May 22, 2017.

23. Udeh EI, Onwujekwe OE, Adewole DA, Onoka CA. Exploring the threshold premium for viable community based health insurance schemes in Nigeria. BMC Res Notes. 2016;9:383.

24. Criel B. District-based health insurance in sub-Saharan Africa, Part II In: Van Lerberghe W, Kegels G, De Brouwere V, editors. Case-studies, Studies in Health Services Organisation \& Policy. Antwerpen: ITGPress; 1998:52-59.

25. Dong H, Kouyate B, Snow R, Mugisha F, Sauerborn R. Gender's effect on willingness-to-pay for community-based insurance in Burkina Faso. Health Policy. 2003;64(2):153-162.

26. Onwujekwe O, Onoka C, Uzochukwu B, Okoli C, Obikeze E, Eze S Is community-based health insurance an equitable strategy for paying for healthcare? Experiences from southeast Nigeria. Health Policy. 2009;92(1):96-102.
ClinicoEconomics and Outcomes Research

\section{Publish your work in this journal}

ClinicoEconomics and Outcomes Research is an international, peerreviewed open-access journal focusing on health technology assessment, pharmacoeconomics and outcomes research in the areas of diagnosis, medical devices, and clinical, surgical and pharmacological intervention. The economic impact of health policy and health systems

\section{Dovepress}

organization also constitute important areas of coverage. The manuscript management system is completely online and includes a very quick and fair peer-review system, which is all easy to use. Visit http://www.dovepress.com/testimonials.php to read real quotes from published authors. 